\title{
A pilot study of estrogen receptor (ER) expression in pancreatic ductal adenocarcinoma (PDAC)
}

\author{
Kai Siang Chan ${ }^{1}$, Bernard Chi Shern $\mathrm{Ho}^{2}$, Vishal G. Shelat ${ }^{3}$ \\ ${ }^{1}$ Lee Kong Chian School of Medicine, Nanyang Technological University, Singapore, Singapore; ${ }^{2}$ Department of Pathology, ${ }^{3}$ Department of General \\ Surgery, Tan Tock Seng Hospital, Singapore, Singapore \\ Contributions: (I) Conception and design: VG Shelat; (II) Administrative support: None; (III) Provision of study materials or patients: BCS Ho, VG \\ Shelat; (IV) Collection and assembly of data: BCS Ho; (V) Data analysis and interpretation: All authors; (VI) Manuscript writing: All authors; (VII) \\ Final approval of manuscript: All authors. \\ Correspondence to: Vishal G. Shelat. Department of General Surgery, Tan Tock Seng Hospital, Singapore 308433, Singapore. \\ Email: vishal_g_shelat@ttsh.com.sg.
}

\begin{abstract}
Background: Pancreatic ductal adenocarcinoma (PDAC) is the most common pancreatic neoplasm with 5 -year survival as low as $6 \%$. It is therefore imperative to explore potential treatment avenues to improve survival in these groups of patients. Anti-estrogenic hormone therapy (AEHT) is well-tolerated and has been used in estrogen receptor (ER) subgroups of breast cancer. ER is a type of sex hormone receptor which have been reported to be expressed inconsistently in pancreatic cancer. This study aims to identify the presence of ER in PDAC specimens to guide potential use of AEHT in the management of unresectable PDAC.

Methods: This is a retrospective case control study of 10 patients ( 5 males, 5 females) who underwent pancreatic resections for PDAC from 2011 to 2012. Sections of the post-operative specimens were prepared and sent for ER staining. Pancreatic tissue specimens that were analysed included (I) ductal epithelial cells; (II) acinar cells; (III) islet cells; (IV) intralobular stromal cells; and (V) adenocarcinoma cells.

Results: Intralobular stromal cells were positively stained for ER in 7/10 (70\%) of the cases, but were of weak intensity and patchy in distribution. Islet cells $(<1 \%)$ stained for ER in 3/10 (30\%) of the cases. Ductal epithelial cells, acinar cells and adenocarcinoma cells stained negative for ER in all of the cases.

Conclusions: This pilot study did not detect the presence of ER expression in PDAC. ER expression in intralobular stromal and islet cells which was previously unreported, were noted in our study. The role of AEHT in pancreatic cancer remains uncertain and does not appear to be of value at present.
\end{abstract}

Keywords: Estrogen receptor (ER); hormonal therapy; pancreatic cancer

Received: 01 November 2019; Accepted: 10 February 2020; Published: 05 January 2021.

doi: $10.21037 /$ tgh.2020.02.16

View this article at: http://dx.doi.org/10.21037/tgh.2020.02.16

\section{Introduction}

Pancreatic ductal adenocarcinoma (PDAC) is the most common pancreatic neoplasm with 5 -year survival as low as $6 \%(1,2)$. The low 5 -year survival rate is often due to late diagnosis and only $20 \%$ of the patients are eligible for surgical resection (2). Over the past two decades, advances have been made in molecular genetics, pharmaco-oncology and peri-operative care. However, survival rates remain dismal due to the lack of screening modalities, advanced stage of disease at presentation and aggressive tumour biology (3). It is therefore imperative to explore potential treatment avenues to improve survival in these groups of patients. Anti-estrogenic hormone therapy (AEHT) is a potential treatment alternative which has demonstrated improved recurrence-free survival in breast cancer in estrogen receptor (ER) positive subgroups (4), and is welltolerated by patients (5).

Sex hormone receptors are expressed in a myriad of 


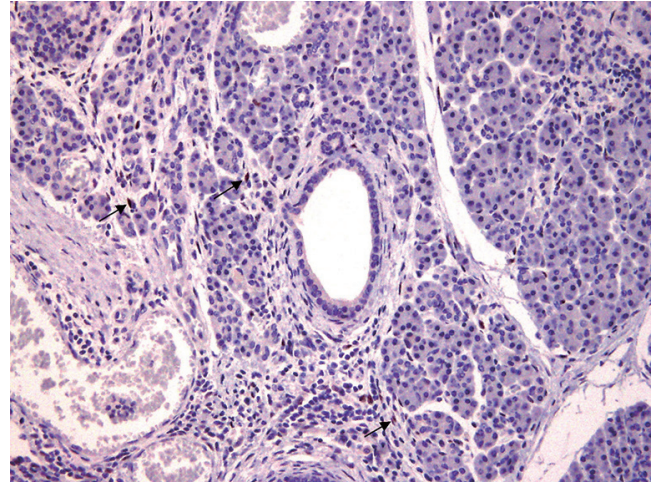

Figure 1 Intralobular cells showing weak expression of estrogen receptor (ER) (black arrows), $\times 200$ magnification

cancers, including pancreatic cancer (6). ER is a type of sex hormone receptor which have been reported to be expressed in pancreatic cancer, though there have been inconsistencies in their detection $(7,8)$. Presence of ER expression in PDAC may potentially guide treatment with AEHT. Several studies have been conducted to explore the role of AEHT (mainly tamoxifen) in the management of PDAC; however, results are equivocal with varying treatment response across different studies (9-16). It has been postulated that the inconsistent results may be attributed to the lack of assessment of estrogen dependence in PDAC (17). Hence, this study aims to identify the presence of ER in PDAC specimens to guide potential use of AEHT in the management of unresectable PDAC.

\section{Methods}

This is a retrospective case control study of 10 patients (5 males, 5 females) who underwent pancreatic resections for PDAC. A list of patients diagnosed with PDAC as per the ICD-10 (International Classification of Diseases, 10th Revision) codes and who underwent pancreatic resections from 2011 to 2012 were generated from the lead authors operative $\log (18)$. Five male and 5 females were randomly selected from the list of patients generated. It has been welldescribed in literature that a minimum sample size of $10-12$ for pilot studies provides the ability to test a hypothesis (19-21). Presence of ER expression in $\geq 2$ of the 10 PDAC specimens will clinically justify further studies involving the use of AEHT in the management of PDAC. Post-operative specimens are preserved for a minimum of seven years by the Department of Pathology in our institution. Specimens with inadequate tissue volume were excluded from the study. Upon completion of the patient selection, sections of the post-operative specimens were prepared and sent for ER staining. This study was approved by the hospital institutional review board (reference number: 2012/00919) and funded by the National Research Foundation Scholarship Grant.

\section{Specimen preparation}

Sections of pancreatic cancer including adjacent normal pancreatic tissue were cut from formalin fixed, paraffin embedded tissue blocks and stained for ER using Novocastra Liquid Mouse Monoclonal Antibody Estrogen Receptor $^{\mathrm{TM}}$ (Product code: NCL-L-ER-6F11) (Leica Biosystems, Newcastle Upon Tyne, UK) and Ventana OptiView DAB IHC Detection Kit ${ }^{\mathrm{TM}}$ (Ventana Medical Systems, Arizona, USA) with appropriate tissue controls. Pancreatic tissue specimens that were analysed included (I) ductal epithelial cells; (II) acinar cells; (III) islet cells; (IV) intralobular stromal cells; and (V) adenocarcinoma cells. Reporting of ER staining was performed in accordance to ER staining for breast cancer specimens (22): (I) proportion of cells (0-100\%) with ER positive nuclear staining and (II) intensity of staining (weak, moderate and strong). Specimen preparation and histopathological analysis were performed by a single, blinded pathologist.

\section{Results}

Intralobular stromal cells were positively stained for ER in $7 / 10(70 \%)$ of the cases; these were stromal spindly cells, all of which had nuclear ER-positive staining were of weak intensity and were patchy in distribution (Figure 1). Islet cells $(<1 \%)$ stained for ER in 3/10 (30\%) of the cases (Figure 2). Ductal epithelial cells, acinar cells and adenocarcinoma cells stained negative for ER in all of the cases (Figure 3). ER positive cells were noted in both normal pancreatic tissue and areas of chronic inflammation adjacent to the pancreatic adenocarcinoma cells.

\section{Discussion}

In this pilot study, PDAC did not express ER. ER is present in some of the normal pancreatic tissues (intralobular stromal cells $7 / 10$, islet cells $3 / 10$ ). To our knowledge, current studies do not show expression of ER limited to intralobular stromal cells and islet cells. It is possible that islet cells may have been incorrectly identified due 


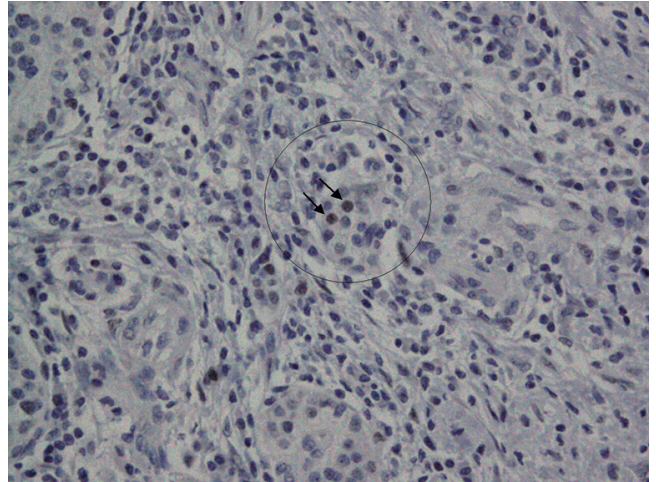

Figure 2 Islet cells showing occasional nuclear estrogen receptor (ER) positivity (black arrow), $\times 400$ magnification.

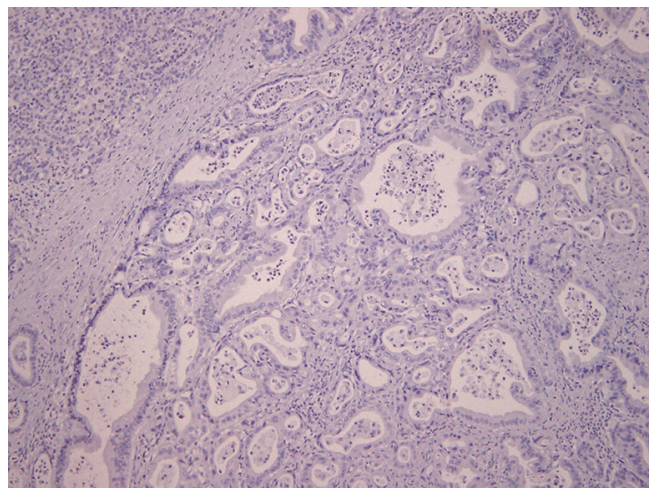

Figure 3 Pancreatic ductal adenocarcinoma cells showing lack of estrogen receptor $(\mathrm{ER})$ staining, $\times 100$ magnification.

to lack of confirmatory staining with anti-insulin or antiglucagon antibodies. However, it has described in literature that the use of antibody-staining techniques may not be necessary (23); islet cells can be easily identified with background counter stain by a trained pathologist. Negative staining for ER in ductal epithelial and acinar cells may be due to the true absence of ER or very low quantities of ER which is undetectable by the immunohistochemical technique.

It is still uncertain whether the ER expression is present in all patients with PDAC. A study by Greenway et al. failed to demonstrate presence of ER receptors at five different sites in a patient with underlying PDAC (7). Our pilot study is also supported by the studies by Singh $e$ al. (8), and Taylor et al. (24), which detected little to no ER expression by immunohistochemistry. The lack of ER staining in our pilot study is unlikely due to the specimen preparation and immunohistochemistry analysis: adequate tissue controls were used to identify problems with tissue fixation with formalin; this is of important significance as it is widely documented that ER is labile and good fixation is required to identify its presence (25). Use of immunohistochemistry for ER performed formalin fixed paraffin embedded tissue has also been documented to be a reliable and convenient method to study ER expression (26).

The role of AEHT in PDAC is still uncertain. Existing studies thus far show equivocal evidence on its use in the management of unresectable PDAC. A study by Wong et al. demonstrated that tamoxifen prolongs survival in postmenopausal women $(n=6 / 15,3$ with minimum 2 -year survival) with unresectable PDAC (12). However, other randomized studies fail to demonstrate the survival benefit of tamoxifen in unresectable pancreatic adenocarcinoma $(15,24)$. The lack of survival benefit in patients treated with tamoxifen could be attributed to the lack of ER expression, as demonstrated in the study by Taylor $e t a l$. (ER expression positive in $n=0 / 25$ ) (24). It was traditionally postulated that the role of tamoxifen in breast cancer is due to its effect on nuclear ERs (27). However, a recent translational study by Cortes et al. in 2019 on mice demonstrated that a new mechanism of action of tamoxifen which is independent of its effect on nuclear ERs (28); this involves a mechanical downregulation of hypoxia-inducible factor-1 alpha (HIF-1A) which reduces the adaptive response of PDAC to hypoxia and may be responsible for reprogramming of the tumour microenvironment and its therapeutic role in some of studies which documented survival benefit of tamoxifen in PDAC. Other mechanisms of action on the role of tamoxifen in cancer treatment have also been described (29).

The presence of ER expression in other organs have also guided several investigations on the role of antihormonal therapy (6). However, these results have been dismal. A randomized control trial on the use of tamoxifen in hepatocellular carcinoma (HCC) by the Cancer of the Liver Italian Programme Group in 1998 (30), and a multicentre regional randomized control trial by Chow et al. in 2002 demonstrated the lack of survival benefits in HCC (31); the latter involved the use of high-dose tamoxifen which inhibits HCC via ER-independent mechanisms.

One of the limitations of this study is that only a single pathologist was involved in the histopathological analysis of the specimens. However, it has been demonstrated that a second opinion surgical pathology is unlikely to change diagnosis with an overall incidence of $1.4 \%$ of 
changed diagnoses, and an even lower incidence of changed diagnosis for gastrointestinal (1.2\%) and endocrine $(0 \%)$ pathologies (32). Due to the small sample size in this pilot study, this is likely to be unremarkable. In addition, this is a pilot study with a small sample. A larger sample would be ideal for detecting the presence of ER staining but this is limited by inadequate funding to permit ER staining for all the patients who underwent pancreatic resections for PDAC. Furthermore, a sample size of ten was determined to be acceptable for a pilot study (19-21).

In conclusion, this pilot study did not detect the presence of ER expression in PDAC. Hence, we were unable to procced to explore AEHT role in management of ERpositive PDAC. The role of AEHT in pancreatic cancer remains uncertain and does not appear to be of value at present. Our study demonstrates the presence of ER expression in intralobular stromal and islet cells, which was previously unreported. Further studies are required to determine the significance of weak and patchy ER expression in intralobular stromal and islet cells.

\section{Acknowledgments}

Funding: This study is funded by the National Research Foundation Scholarship Grant.

\section{Footnote}

Provenance and Peer Review: This article was a free submission to the journal. The article has undergone external peer review.

Conflicts of Interest: All authors have completed the ICMJE uniform disclosure form (available at http://dx.doi. org/10.21037/tgh.2020.02.16). The authors have no conflicts of interest to declare.

Ethical Statement: The authors are accountable for all aspects of the work in ensuring that questions related to the accuracy or integrity of any part of the work are appropriately investigated and resolved. The study was conducted in accordance with the Declaration of Helsinki (as revised in 2013). This study was approved by the hospital institutional review board(reference number: 2012/00919). The written informed consent was waived due to the retrospective nature of the study.

Open Access Statement: This is an Open Access article distributed in accordance with the Creative Commons Attribution-NonCommercial-NoDerivs 4.0 International License (CC BY-NC-ND 4.0), which permits the noncommercial replication and distribution of the article with the strict proviso that no changes or edits are made and the original work is properly cited (including links to both the formal publication through the relevant DOI and the license). See: https://creativecommons.org/licenses/by-nc-nd/4.0/.

\section{References}

1. Kamisawa T, Wood LD, Itoi T, et al. Pancreatic cancer. Lancet 2016;388:73-85.

2. Gillen S, Schuster T, Zum Büschenfelde CM, et al. Preoperative/neoadjuvant therapy in pancreatic cancer: a systematic review and meta-analysis of response and resection percentages. PLoS Med 2010;7:e1000267.

3. Alexakis N, Halloran C, Raraty M, et al. Current standards of surgery for pancreatic cancer. Br J Surg 2004;91:1410-27.

4. Rose C, Mouridsen HT, Thorpe SM, et al. Anti-estrogen treatment of postmenopausal breast cancer patients with high risk of recurrence: 72 months of life-table analysis and steroid hormone receptor status. World J Surg 1985;9:765-74.

5. Hortobagyi GN. Treatment of breast cancer. N Engl J Med 1998;339:974-84.

6. Stedman KE, Moore GE, Morgan RT. Estrogen receptor proteins in diverse human tumors. Arch Surg 1980;115:244-8.

7. Greenway B, Iqbal M, Johnson $\mathrm{P}$, et al. Oestrogen receptor proteins in malignant and fetal pancreas. Br Med J (Clin Res Ed) 1981;283:751-3.

8. Singh S, Baker P, Poulsom R, et al. Expression of oestrogen receptor and oestrogen-inducible genes in pancreatic cancer. Br J Surg 1997;84:1085-9.

9. Theve NO, Pousette A, Carlström K. Adenocarcinoma of the pancreas--a hormone sensitive tumor? A preliminary report on Nolvadex treatment. Clin Oncol 1983;9:193-7.

10. Tønnesen K, Kamp-Jensen M. Antiestrogen therapy in pancreatic carcinoma: a preliminary report. Eur J Surg Oncol 1986;12:69-70.

11. Crowson MC, Dorrell A, Rolfe EB, et al. A phase II study to evaluate tamoxifen in pancreatic adenocarcinoma. Eur J Surg Oncol 1986;12:335-6.

12. Wong A, Chan A, Arthur K. Tamoxifen therapy in unresectable adenocarcinoma of the pancreas. Cancer Treat Rep 1987;71:749-50. 
13. Keating JJ, Johnson PJ, Cochrane AM, et al. A prospective randomised controlled trial of tamoxifen and cyproterone acetate in pancreatic carcinoma. Br J Cancer 1989;60:789-92.

14. Scheithauer W, Kornek G, Haider K, et al. Unresponsiveness of pancreatic adenocarcinoma to antioestrogen therapy. Eur J Cancer 1990;26:851-2.

15. Bakkevold KE, Pettersen A, Arnesjø B, et al. Tamoxifen therapy in unresectable adenocarcinoma of the pancreas and the papilla of Vater. Br J Surg 1990;77:725-30.

16. Wong A, Chan A. Survival benefit of tamoxifen therapy in adenocarcinoma of pancreas. A case-control study. Cancer 1993;71:2200-3.

17. Yamashita J, Abe M, Ogawa M. Endocrine therapy in pancreatic carcinoma. Oncology 1998;55:17-22.

18. World Health Organization. ICD-10: international statistical classification of diseases and related health problems: tenth revision. 2004. Available online: https://apps.who.int/iris/bitstream/ handle/10665/42980/9241546530_eng.pdf

19. Isaac S, Michael WB. Handbook in research and evaluation: A collection of principles, methods, and strategies useful in the planning, design, and evaluation of studies in education and the behavioral sciences. Edits publishers; 1995.

20. Julious SA. Sample size of 12 per group rule of thumb for a pilot study. Pharmaceut Statist 2005;4:287-91.

21. Van Belle G. Statistical rules of thumb. John Wiley \& Sons; 2011.

22. Barnes DM, Harris WH, Smith $\mathrm{P}$, et al. Immunohistochemical determination of oestrogen receptor: comparison of different methods of assessment of staining and correlation with clinical outcome of breast cancer patients. Br J Cancer 1996;74:1445-51.

23. Baskin DG. A historical perspective on the identification of cell types in pancreatic islets of Langerhans by staining and histochemical techniques. J Histochem Cytochem

doi: $10.21037 / \operatorname{tgh} .2020 .02 .16$

Cite this article as: Chan KS, Ho BCS, Shelat VG. A pilot study of estrogen receptor (ER) expression in pancreatic ductal adenocarcinoma (PDAC). Transl Gastroenterol Hepatol 2021;6:9.
2015;63:543-58.

24. Taylor O, Benson E, McMahon M. Clinical trial of tamoxifen in patients with irresectable pancreatic adenocarcinoma. Br J Surg 1993;80:384-6.

25. King WJ, DeSombre ER, Jensen EV, et al. Comparison of immunocytochemical and steroid-binding assays for estrogen receptor in human breast tumors. Cancer Res 1985;45:293-304.

26. Taylor CR, Shi SR, Chaiwun B, et al. Strategies for improving the immunohistochemical staining of various intranuclear prognostic markers in formalinparaffin sections: androgen receptor, estrogen receptor, progesterone receptor, $\mathrm{p} 53$ protein, proliferating cell nuclear antigen, and $\mathrm{Ki}-67$ antigen revealed by antigen retrieval techniques. Hum Pathol 1994;25:263-70.

27. Hall JM, Couse JF, Korach KS. The multifaceted mechanisms of estradiol and estrogen receptor signaling. J Biol Chem 2001;276:36869-72.

28. Cortes E, Lachowski D, Robinson B, et al. Tamoxifen mechanically reprograms the tumor microenvironment via HIF-1A and reduces cancer cell survival. EMBO Rep 2019. doi: 10.15252/embr.201846557.

29. Daurio NA, Tuttle SW, Worth AJ, et al. AMPK Activation and Metabolic Reprogramming by Tamoxifen through Estrogen Receptor-Independent Mechanisms Suggests New Uses for This Therapeutic Modality in Cancer Treatment. Cancer Res 2016;76:3295-306.

30. Group C. Tamoxifen in treatment of hepatocellular carcinoma: a randomised controlled trial. Lancet 1998;352:17-20.

31. Chow PK, Tai BC, Tan CK, et al. High-dose tamoxifen in the treatment of inoperable hepatocellular carcinoma: a multicenter randomized controlled trial. Hepatology 2002;36:1221-6.

32. Kronz JD, Westra WH, Epstein JI. Mandatory second opinion surgical pathology at a large referral hospital. Cancer 1999;86:2426-35. 